\title{
CERVEJEIROS ARTESANAIS: recursos, percursos e empresarialização de si
}

\author{
CRAFT BREWERS: \\ courses, resources and strategies of entrepreneur of self
}

\author{
Andrey Felipe Sgorla*
}

\begin{abstract}
Resumo
A pesquisa analisa aspectos da construção do mercado de cervejas artesanais no Brasil, a partir dos percursos de empresarialização de cervejeiros artesanais, dos valores e representações nos quais, a partir de uma estrutura de oportunidades sociais, econômicas e de recursos permitem a transformação de um hobby em uma atividade empresarial. A estratégia metodológica inspirada no trabalho de Lahire, por meio de entrevistas em profundidade, busca explorar as diversas esferas da vida de seus entrevistados e, ao reconstruir as trajetórias de vida, retratar a construção do mercado de cervejas artesanais, enfatizando as semelhanças, as diferenças, as diversidades e continuidades de um processo que está acontecendo globalmente, mas que adquire características dos locais onde as cervejarias são instaladas. A expansão de microcervejarias nesta década é decorrente de um percurso de empresarialização de cervejeiros artesanais, que transformam um hobby de fazer cerveja em casa, em panelas, em uma nova carreira, reconvertendo suas trajetórias profissionais para a identificação como cervejeiro artesanal, responsável pela abertura de novas microcervejarias, utilizando-se do conhecimento e das habilidades aprendidas e desenvolvidas neste fazer artesanal.
\end{abstract}

Palavras-chave: Cervejas artesanais. Cervejeiros. Empresarialização. Trajetórias Profissionais.

\begin{abstract}
The research analyzes the development of the craft beer market in Brazil based on the corporatization paths of craft brewers, values and actions which, from a structure of social, symbolic, economic and resource opportunities, enable the transformation of a hobby into a business activity. The methodological strategy inspired by Lahire's work, exploring the diverse spheres of life of its respondents through in-depth interviews and reconstructing life trajectories, portrays the construction of the craft beer market, emphasizing the similarities, differences, diversities and continuities of a process that is going on globally, but rooted in local processes. The expansion of microbreweries in this decade is due to the entrepreneurial course of artisanal breweries, which transform a hobby of brewing beer at home, in pans, into a new career, by converting professional trajectories into identification as a brewery artisan, responsible for opening new microbreweries, using the knowledge and skills learned and developed in this craft.
\end{abstract}

Keywords: Craft beers. Brewers. Entrepreneurship. Professional Trajectories.

Ao entrar em uma loja de cervejas ou em um supermercado, no corredor dessas bebidas, muitas vezes há dezenas de cervejas artesanais, sejam elas nacionais ou importadas. Além disso, a categorial artesanal possui um preço superior e é mais complexa que as tradicionais. $\mathrm{O}$ rótulo sobre uma garrafa de cerveja artesanal apresenta, muitas vezes, uma grande quantidade de informações, incluindo o estilo (por exemplo, "American IPA"), amargor ("IBU 55" é um

\footnotetext{
* Professor de Sociologia na Faculdade Murialdo, Caxias do Sul, RS, Brasil.Mestre e Doutorando em Ciências Sociais pela PUCRS. E-mail: afsgorla@gmail.com.
} 
exemplo), intensidade da cor (como a "30"), nome da cerveja (por exemplo, "Green Cow"), graduação alcoólica (“7,2\%”, por exemplo), o nome da cervejaria (por exemplo, "Dois Corvos") e tipo de copo para beber a cerveja (como a "tulipa"). Uma cerveja artesanal também apresenta, em seu rótulo, selos ${ }^{1}$, incluindo prêmios recebidos em concursos nacionais e internacionais que, muitas vezes, agregam valor ao preço da cerveja.

Os cientistas sociais, há muito tempo, reconheceram que transações econômicas envolvem mais do que uma simples troca de bens ou serviços por dinheiro, o que enfatiza o caráter simbólico de determinadas trocas econômicas (MALINOWSKI, 1976; GEERTZ, 2008; SAHLINS, 2003; DOUGLAS, ISHERWOOD, 2004). Alguns autores têm trabalhado dentro da nova sociologia econômica, dando continuidade a esta tradição, examinando como valores culturais afetam a vida econômica, tanto nos processos de interação social, como nas dinâmicas dos mercados (ZELIZER, 2009; VELTHUIS, 2005).

O mercado de cervejas artesanais é recente e seu crescimento ocorreu na última década. Dados do Sebrae (2015) indicam a existência de 300 microcervejarias no Brasil; a Associação Gaúcha de Cervejas Artesanais indica a existência de 80 microcervejarias no Rio Grande do Sul. Ainda que as pioneiras deste modelo tenham 20 anos, como a cervejaria Dado Bier de Porto Alegre e a Cervejaria Colorado, em Ribeirão Preto/SP, a expansão deste mercado ocorreu, nos últimos cinco anos, com a abertura, por exemplo, de doze microcervejarias em Porto Alegre.

Inicialmente, este processo aconteceu nos Estados Unidos, com a abertura da primeira microcervejaria, Anchor Brewing Beer, no ano de 1971 (CARROL e SWAMINATHAN, 2000). O mercado cervejeiro estava concentrado em poucas cervejarias, que produziam uma cerveja intitulada "industrial". As pequenas cervejarias nasceram para oferecer aos consumidores uma maior variedade em sabor, cor, espuma, nível de álcool e temperatura de servir. O termo microcervejaria indicava, no início, pequenas cervejarias, com produção reduzida, mas logo apontou uma nova atitude na fabricação de cerveja, com base na inovação, na criatividade e qualidade, especializada em ofertar produtos para um mercado específico (CARROL e SWAMINATHAN, 2000). Posteriormente, este movimento espalhou-se para vários países, incluindo Itália, Alemanha, Dinamarca, Noruega, França, China, Japão, Austrália, Reino Unido, Bélgica e, mais recentemente, em Portugal, com o propósito de criar pequenas fábricas de cerveja de alta qualidade, que seguem tendências globais, regradas por estilos de cervejas, mas que são adequadas aos paladares e aos ingredientes dos locais em que estão inseridas.

Segundo Carroll e Swaminathan (2000), em seus estudos sobre microcervejarias americanas, os consumidores deste tipo de cerveja reagem fortemente contra os produtores em massa, que ofertam um produto padronizado, de baixo custo e livre de falhas no processo de fabricação, alcançado através da pasteurização. Buscam um valor de qualidade "autêntico" de

1 Os selos são utilizados para validar a qualidade do produto, a partir da avaliação do respectivo rótulo por uma equipe de avaliadores que chancelam a qualidade do produto. O selo "não certifica apenas um produto, uma forma de produzir, mas chancela e coloca em relevo uma rede de indivíduos e organizações que partilham determinados valores e uma visão de mundo" (SCHNEIDER, 2015, p.3). 
cervejas artesanais, são muito sensíveis às qualidades organolépticas, matérias-primas e em busca de recursos tangíveis do produto em si, que são percebidos como priorizando outros valores e não apenas o lucro. O consumo de cervejas artesanais também está associado à experiência da degustação e da distinção; portanto, de um certo estatuto social - o paralelo de ser um aficionado por vinho, queijo, música ou arte.

Os estudos sobre nicho de mercado, desenvolvidos especialmente por Carrol (1985), indicam que as empresas que demonstrem o compromisso através de ofertas superiores e/ ou conhecimento podem ganhar diferenciação dentro do nicho. Além disso, a literatura indica fortemente que satisfaçam as necessidades dos consumidores dentro de um segmento de nicho de forma positiva, este se correlaciona com o consumidor, criando uma autoidentificação com a oferta e o fornecedor, e que será um fator determinante da satisfação do cliente inserido neste nicho.

Neste estudo, o principal objetivo é analisar a construção do mercado de cervejas artesanais, a partir dos percursos de empresarialização de cervejeiros artesanais, dos valores e representações os quais, a partir de uma estrutura de oportunidades sociais, econômicas e de recursos, permitem a transformação de um hobby em uma atividade empresarial.

\section{Metodologia}

Para elaborar esta pesquisa sobre os percursos de empresarialização dos cervejeiros artesanais e da construção social do mercado de cervejas artesanais, realizei incursões etnográficas no campo de pesquisa, por meio de mapeamento de cervejarias localizadas no Rio Grande do Sul, visitas a cervejarias, participação de eventos cervejeiros e incursões netnográficas em três grupos de cervejas artesanais no Facebook, páginas de cervejarias, perfis de cervejeiros e em grupos de e-mails, para acompanhar as discussões existentes nestes espaços e identificar quais as temáticas das publicações. Estas compreendem uma grande variedade de assuntos, tais como: eventos de degustação de cervejas, divulgações de cursos, novos rótulos de cervejas, novas cervejarias, processos de fabricação, tipos de malte e de lúpulo, receitas, tributação de cervejas, processo de abertura de cervejaria, uma grande variedade de assuntos.

A partir desta incursão inicial, definiu-se a estratégia metodológica para a realização da pesquisa, inspirada no trabalho de Lahire, que procurou realizar entrevistas ${ }^{2}$ sucessivas em profundidade, explorando as diversas esferas da vida de seus entrevistados e, ao reconstruir as trajetórias de vida dos cervejeiros, explicar como as disposições que elas apresentam hoje foram construídas ao longo dessas trajetórias. Trata-se, assim, de "estudar o social à escala individual" (LAHIRE, 2002; 2005), através de concepções de indivíduo, retratadas na construção do mercado de cervejas artesanais. Neste estudo, pretendemos enfatizar as semelhanças, as

$2 \mathrm{Na}$ pesquisa entrevistamos dez proprietários de microcervejarias, uma sommelier de cerveja proprietária de um bar, ao longo do ano de 2017. Além das entrevistas, participamos de oito festivais de cerveja artesanal, visitamos dez cervejarias, acompanhamos as páginas do Facebook das cervejarias e dos cervejeiros escolhidos para a pesquisa. 
diferenças, as diversidades e continuidades de um processo de expansão global do mercado de cervejas artesanais, mas que está profundamente enraizado nos processos locais. Identificamos que o mercado de cervejas artesanais se insere em um processo de neolocalismo. Segundo Schell (2013), este processo consiste na conscientização de indivíduos e de grupos para estabelecer, reconstruir e cultivar laços e identidades locais, e cada vez mais apoiar as economias locais, em contraponto ao efeitos de homogeneização da globalização.

Desta forma, os percursos de vida à empresarialização de si e à inserção profissional dos cervejeiros artesanais, os recursos e capitais mobilizados, as questões de classe social e gênero, os sentidos e os valores, e as condições para a construção destas novas carreiras não se reproduzem da mesma forma e adquirem feições locais.

Segundo LAHIRE (2004, p. 34), usar "um dispositivo metodológico inédito", que consiste na realização de entrevistas longas e sucessivas com cada um dos entrevistados sobre temáticas do mundo das cervejas, de forma geral, orienta a investigação para a obtenção do melhor conjunto possível de informações, evidências e indícios, com potencial de subsidiar interpretações adequadas acerca do "patrimônio de disposições" do pesquisado.

De acordo com Lahire (1997, p.18), "a maneira pela qual construímos sociologicamente nosso objeto, leva-nos também a refletir sobre a pluralidade das formas de vida social e forma de pensamento e comportamento". Desta forma, a pesquisa oportunizará a construção deste olhar, indo ao encontro da heterogeneidade e complexidade que são os contextos das trajetórias dos cervejeiros profissionais.

Na perspectiva de Lahire (2006), a mudança de escala de observação oferece a imagem do mundo social, que pode ser produzida por um olhar que examina as diferenças internas de cada indivíduo, as suas variações intraindividuais, e enfoca as diferenças entre classes sociais, denominadas de variações interclasses.

Os perfis apresentaram-se como um subsídio de análise teórico-metodológica, na tentativa de apresentar o que é singular, individual, suas interfaces e contradições para explorar as questões sociais e complexas que envolvem as relações sociais. A escrita dos perfis pressupõe uma prática que propicia "a leitura de um traço subjetivo (relação particular com os outros ou com certos tipos de situação) ou objetivo (posição social ou tipo de trajetória) próprio ao entrevistado" (LAHIRE, 2004, p.45).

Para Dubet (1996), a experiência "é uma atividade cognitiva, uma maneira de construir o real e, sobretudo, de o verificar, de o experimentar" e "constrói fenômenos a partir de categorias do entendimento e da razão, é uma maneira de construir o mundo" (DUBET, 1996, p. 95). Todavia, ela "não é expressão de um sujeito puro, mas é socialmente construída" (idem, p. 103), pois somente "é reconhecida pelos outros, eventualmente partilhada e confirmada por outros (idem, p. 104)".

Segundo Ferreira (2014), a técnica qualitativa para compreendermos a experiência dos sujeitos pesquisados é 
A aplicação da entrevista de tipo compreensivo pressupõe a obtenção de um discurso mais narrativo que informativo, resultado da intersubjectividade que se desenrola entre entrevistado e entrevistador. Tal exercício pressupõe, da parte do entrevistador, uma postura criativa e de improvisação na condução da entrevista, que requer artes e manhas específicas. (FERREIRA, 2014, p. 979).

Neste sentido, buscaremos uma compreensão sobre os saberes que os sujeitos constroem nas suas trajetórias, compreendendo a experiência do outro e aprendendo com ela, construindo um conhecimento entre os saberes dos biografados com o do autor.

\section{Empresários de si e identidade cervejeira}

Os cervejeiros artesanais, ao definirem-se desta forma, podem ser designados empresários de si (ALVES, 2009), cuja forma identitária assenta na valorização do trabalho independente. A transação biográfica que a sustenta dá visibilidade a uma identidade para si como cervejeiro artesanal e que exerce uma profissão, na qual são atores imersos em uma estrutura de relações sociais que constrói uma identidade para si e para os outros, relacionada com as suas cervejas e o mercado de cervejas artesanais.

O cervejeiro "Pumpkin", publicitário, professor universitário e dono de agência de publicidade, inicialmente produzia cerveja em casa, com recursos próprios adquiriu as panelas, comprou os insumos, realizou um curso sobre fabricação de cervejas. Quando iniciou a produção, era para consumo próprio. No segundo momento, mesmo sem os registros legais da cervejaria, começa a vender para os amigos. Com o aumento da demanda, no último ano (2017), iniciou a produção em uma fábrica de terceiros, investindo os recursos obtidos na venda da cerveja para produzir mais cervejas. Ao relatar o início de sua produção, destaca a preocupação em elaborar receitas únicas, exclusivas, que relacionem um estilo de cerveja com a identidade da marca da cervejaria.

\footnotetext{
Quando eu comecei a fazer cerveja, eu me preocupei em fazer uma pesquisa, quem eram as cervejarias aqui no mercado, e que tipo de cerveja elas vendiam. Porque eu pensei assim, se eu começar a fazer igual a eles, os caras me sufocam. Vou fazer uma Pilsen. O cara ali faz milhares de litros de Pilsen, muito mais barato que eu, para quê? Por isso, a ideia de fazer coisas diferentes. Fazer uma Stout, fazer uma pumpkin, uma fruit bier, são tudo cervejas que tu não vais encontrar. E a minha ideia de cerveja é isso, de trazer uma experiência diferente para a pessoa.
}

Esta identidade justifica-se através dos caminhos percorridos, pois pretendem obter seu reconhecimento, relacionado com o contexto da fabricação de cerveja, através dos aspectos importantes da natureza do seu trabalho, que remetem a uma sensação de recompensa e satisfação encontrada na produção, que resulta em um produto distinguido pelas competências, na separação dos ingredientes, na elaboração das receitas, a paixão e o cuidado implantado em sua elaboração. 
A identidade de empresário de si tem, no princípio da autonomia, o seu elementochave, ao mudar de carreira e valorizar o trabalho por conta própria, da flexibilidade de horário, do controle do ritmo de trabalho, da inexistência de relações hierárquicas, dos rendimentos instáveis, da crença numa relação virtuosa entre trabalho, mérito e salário e da responsabilização individual. Contudo, ser soberano de si próprio implica em assumir a total responsabilidade pelos respectivos sucessos e fracassos, e estes dependem quase exclusivamente do reconhecimento público das suas competências profissionais e da sua capacidade de se vender enquanto produto. As relações com os consumidores são, por isso, o espaço social de reconhecimento socioprofissional e a "marketização do eu", a estratégia que permite ter sucesso num mercado fortemente concorrencial, o que implica não só vender-se como um produto, mas também gerir-se como uma empresa, e encerrar em si mesmo todas as áreas funcionais de uma empresa. Por isso, eles são responsáveis pela produção e pelo marketing, pela gestão de recursos humanos e pela gestão financeira. Eles definem o horário e a organização do trabalho; eles desenham campanhas de marketing; eles decidem sobre o seu investimento em formação e gerem autonomamente as suas carreiras; eles concebem estratégias de negócio que analisam e reformulam em função dos resultados. (ALVES, 2009).

$\mathrm{Na}$ entrevista com o cervejeiro "Pumpkin", ele descreve a relação complementar entre o cervejeiro e o profissional de marketing, sua profissão inicial, e que influência houve na construção de sua marca de cervejas.

O Pumpkin olha para a cerveja como uma coisa diferente, como talvez um hobby diferente. O Pumpkin profissional de comunicação ele já olha aquilo ali como um negócio. Ele começa a olhar não só para a cerveja, mas toda a experiência, o comportamento de marca, embalagem, posicionamento, eu acho que isso me ajuda bastante, porque eu não preciso pagar para alguém fazer isso, eu sou um cara que pensa nisso aí também. Quando eu vou criar uma receita de cerveja, eu consigo trazer o "Pumpkin cervejeiro" e o "Pumpkin profissional", os dois juntos.

O desejo de ser empresário de si dá visibilidade a um sistema de crenças que se fundamenta na autonomia e na iniciativa, da individualização e da responsabilização individual de que trata Beck (2011), na qual cada um é responsável por si, num mundo marcado pela incerteza, pelo risco e pela complexidade, que se fundamentam com base num presente onde impera "o novo espírito do capitalismo" (BOLTANSKI e CHIAPELLO, 2009). Eles revelam o apoio aos novos modelos de organização do trabalho e aos princípios que os fundamentam; eles mostram a adesão às novas liturgias sociais: a performance, a soberania e a gestão de si (ALVES, 2009).

O entrevistado "IPA", proprietário de cervejaria localizada em Porto Alegre/RS, graduado e mestre em ciência da computação, trabalhava em uma multinacional da área da tecnologia e largou o emprego para montar a cervejaria. Tinha como sócios a esposa e um casal de investidores que aportaram recursos no início da operação da fábrica para aquisição dos 
primeiros maquinários. A esposa também faz cerveja, porém continua no seu emprego, e auxilia na elaboração de algumas receitas.

\begin{abstract}
Quando eu pensei na ideia de vamos vender cerveja, então tá vamos abrir uma cervejaria. Como é que eu faço? Então tá, vamos escrever o plano de negócios. Comecei a escrever o plano de negócios e comecei a travar na parte de gestão. Porque eu sabia fazer cerveja, mas eu não sabia gerir um negócio, uma pequena indústria. Daí ali que eu senti a necessidade de fazer um curso. Isso em 2008. Aí eu me inscrevi, em 2008, para fazer um curso em 2009, no sentido de me dedicar, aí que eu tomei a decisão de largar o meu emprego. Eu conversei com a minha esposa e disse, cara, não vai dar, esse curso tem um mês de duração, eu vou ficar um mês lá depois, e eu recém tirei férias e a fábrica vai demandar e eu não vou conseguir. Então tá, é o seguinte, vamos sair, vamos se atirar e vamos fazer.
\end{abstract}

Ao mesmo tempo, Claude Dubar (1998, 2005, 2009), ao conceitualizar identidade e formas identitárias, auxilia na compreensão dos significados que os atores atribuem ao processo de que são protagonistas, no qual essas identidades, como as definições que cada um constrói sobre si próprio, são fundadas nas representações do mundo profissional e no lugar que ocupa nesse mesmo mundo. Essas identidades são o resultado da articulação de dois processos: um processo biográfico que permite a construção de uma identidade "para si”, com base nas categorias oferecidas pelas várias instituições, e nas quais o sujeito se revê, e um processo relacional, através do qual se constrói uma identidade "para o outro", assente no reconhecimento de saberes, competências e imagens de si, propostas e expressas pelos indivíduos nos sistemas de ação (DUBAR, 2005).

\title{
As mulheres e o mercado de cervejas artesanais
}

Inicialmente os espaços no mercado de cervejas artesanais eram dominados pelos homens, e as mulheres ocupavam papel marginal na fabricação de cerveja e também como consumidoras. No cenário de uma marginalização de estereótipo, emergiu sobre as mulheres e as capacidades da preferência, um modelo que reforça a dominação masculina: as mulheres não têm o paladar para cerveja, e assim preferem cervejas frutadas ou doces, enquanto os homens, em oposição, preferem o sabor amargo de uma Indian Pale Ale, símbolo de uma cerveja verdadeira, uma cerveja masculina, e da superioridade cultural cervejeira dos homens, pois são eles que têm o poder de designar legitimidade. O perfil de sabor que é considerado legítimo é o que o palato deve conquistar em um masculinadade (MACEL, 2017).

Neste contexto, é criado no âmbito do mercado de cervejas artesanais, o Coletivo ELA (Empreender, Libertar e Agir), organizado por mestres cervejeiras de vários estados do Brasil, com o objetivo de desmistificar o machismo no mercado de cervejas artesanais - seja em rótulos, campanhas publicitárias, produção da bebida ou ainda no tratamento que muitas mulheres recebem como consumidoras. 
Segundo postagem no grupo no Facebook:

ELA é uma cerveja-voz. Voz sonora, alta e feminina. Um grito forte dado por um coletivo de mulheres cervejeiras que querem desmistificar o machismo em um meio em que ele é ainda tão presente, seja em rótulos, campanhas publicitárias ou ainda no tratamento que muitas recebem trabalhando com cerveja ou apenas consumindo, e construir, junto a tantos outros, um mundo de igualdade. Igualdade política, social e de vozes. Esta causa não será silenciada. Essa é a resposta brassada por ELAs.

Este movimento acontece para, a partir de uma identidade feminina e de cervejeira, questionar o consumo e a fabricação de cerveja, marcados como uma construção masculina, podendo esta ser compreendida como um projeto construído e sustentado coletivamente em contextos específicos; entre eles, o mercado de cervejas artesanais, afetando diretamente a inserção de mulheres no mercado de cervejas artesanais.

Identificamos, em nosso trabalho de campo, que as mulheres ${ }^{3}$, ao se inserirem no mercado de cervejas artesanais, originam-se de áreas técnicas como Engenharia de Alimentos, Biologia, Biotecnologia, Farmacologia, atuando como prestadoras de serviços para microcervejarias no manuseio e na seleção dos ingredientes e na melhoria do processo de fabricação. Outro campo de atuação destacado é como sommliere $e^{4}$ ou donas de bares, atuando com a degustação de cervejas, sendo poucas as mulheres donas de cervejarias. Embora não tenhamos dados consolidados, em Porto Alegre, das treze cervejarias localizadas no bairro Anchieta, em apenas uma delas tem uma mulher como sócia, ao mesmo tempo que, atuando nestas cervejarias, no processo de produção, identifiquei cinco mulheres, outras poucas ainda atuam na parte de comunicação e gestão.

A construção desta identidade cervejeira está vinculada ao processo de criação de novas cervejarias, inserido no contexto de empreendedorismo, a partir da identificação de uma oportunidade decorrente de uma ideia inovadora, na qual (VALDEZ, DOKTOR, SINGER, \& DANA, 2011) criam-se novos empreendimentos, que envolvem um perfil individual empreendedor e criativo, no sentido de criar uma cerveja única e inovadora, com a adição de novos ingredientes na elaboração das receitas.

Segundo o cervejeiro "Pumpkin"

Cerveja não é receita, é técnica. Tem coisas particulares das minhas receitas que hoje eu começo a ler. Por exemplo, na literatura americana de cervejas e eu digo, pô, eu já

3 Não existe um levantamento sobre o número de mulheres que atuam no mercado de cervejas artesanais, porém identifiquei nos eventos, nas entrevistas, na abertura de empresa de consultoria para este mercado, a participação em maior número nestas áreas técnicas, do que no setor de produção da fábricas.

4 Sommeliere, profissional especializado em bebidas que trabalha em restaurantes, bares e afins, responsável por garantir a escolha de uma cerveja de boa procedência e qualidade, pelo recebimento da bebida no estabelecimento comercial, pela elaboração da carta de cervejas, pela harmonização com os pratos do cardápio do restaurante e pela verificação se a bebida está pronta e em perfeitas condições de ser servida. 
faço isso faz um tempo, só que eu não tinha lido, eu desenvolvi, como é que eu vou te dizer, por método de tentativa; em 2015, eu fiz 38 cervejas. Ali eu brassei ${ }^{5}$ para caramba. Todo final de semana eu fazia cerveja. E ali eu anotava tudo e via, se eu fizer assim, é melhor do que se eu fizer assado.

Neste processo de desenvolvimento, os cervejeiros não utilizam apenas habilidades físicas, mas conhecimento tácito (POLANYI, 2000) que, muitas vezes adquirido através de prática extensa e formação, permite explorar um conjunto de estímulos sensoriais e corporais, para saber o que fazer e, de modo intuitivo, quando fazê-lo (O’CONNOR, 2005).

\section{O trabalho artesanal}

O conceito de artesanato é utilizado para dar sentido a uma ampla variedade de recursos de trabalho utilizados pelos cervejeiros artesanais que se caracterizam pelos valores relativos à qualidade, atendimento, paixão, habilidade e atenção aos detalhes sensoriais, aromáticos, e na escolha dos ingredientes para elaboração das receitas. Podem trabalhar, na elaboração de receitas, de forma individual ou coletivamente, de forma colaborativa com outras cervejarias, e tendem a valorizar um ambiente de trabalho de autonomia em relação às suas práticas de trabalho e ao seu contributo criativo para o processo de produção.

$\mathrm{O}$ artífice explora essas dimensões de habilidade, empenho, compromisso e avaliação de um jeito específico. Focaliza a relação íntima entre a mão e a cabeça. Todo bom cervejeiro sustenta um diálogo entre práticas concretas e ideias; este hábito evolui para o estabelecimento de hábitos prolongados que, por sua vez, criam um ritmo entre a solução e a detecção de problemas (SENNETT, 2012).

Para Sennett (2012), todas as habilidades, inclusive as mais abstratas, começam como práticas corporais, e a compreensão técnica desenvolve-se através do poder da imaginação. $\mathrm{O}$ primeiro conhecimento viria por meio da mão que manuseia o objeto, o tato a serviço do conhecimento. A imaginação seria a capacidade humana, a partir da linguagem, que tenta orientar a habilidade corporal. Daí a ideia de uma conexão entre a mão e a cabeça, entre o pensamento e a ação. A utilização ou invenção de novas ferramentas viria complementar a exploração das possibilidades do objeto. Esse fato estimula ainda mais a imaginação do artesão, o qual aprende com as dificuldades que o objeto lhe impõe. A resistência e a ambiguidade resultam em uma experiência instrutiva na perspectiva de desenvolver o trabalho.

A entrevistada "Ambar", dona de bar especializado em cervejas artesanais na cidade de Porto Alegre, formada em economia, atuou em bancos, e como os demais entrevistados, o

5 Brassagem é o processo de fabricação da cerveja, a brassagem ou maceração é a parte em que, por meio do cozimento do malte com água quente, convertemos o amido dos grãos em maltose e outros carboidratos que formarão o mosto. 
abandono da carreira na área bancária se deu a partir do descontentamento com o trabalho que realizava. Durante o período de férias realizou cursos de sommelier, em São Paulo, e optou por trocar de carreira, iniciando o trabalho como sommelier em distribuidora de bebidas, e como consultora para bares e restaurantes sobre cartas de cervejas. Recentemente, montou um bar com recursos próprios, oriundos da economia no tempo em que trabalhava no banco.

\begin{abstract}
Da criação de tudo isso que está acontecendo. E eu acho que quando tu trabalha com essa paixão, com esse amor, tu estuda sobre isso e tu consegue passar isso para o teu consumidor. Não é simplesmente um troço feito em massa para ter lucratividade. Tem muito por trás disso. O artesanal é isso. Seja um pão, do pãozeiro,, do nosso parceiro. O artesanal tem história, porque cada uma das coisas é feita com carinho, com estudo, com dedicação, procurando melhorar.
\end{abstract}

O trabalho artesanal, de acordo com Sennett (2012), apresenta três habilidades básicas: localizar, indagar e desvelar. A primeira seria a habilidade de encontrar a matéria; a segunda, a de pensar sobre as suas qualidades; a terceira, a de ampliar seu significado. Para Sennett, as possibilidades e as dificuldades de fazer bem as coisas aplicam-se ao estabelecimento das relações humanas. O que as pessoas precisam é praticar as relações interpessoais e aprender as habilidades de antecipação e revisão, a fim de melhorar tais relações, e aprender a trabalhar de forma cooperativa, compartilhando as informações.

A construção do mercado de cervejas artesanais passa, fundamentalmente, por uma história de construção coletiva, pelas associação de cervejeiros caseiros. No trabalho de campo identifiquei que todos os entrevistados participaram em algum momento da associação de cervejeiros artesanais, especialmente pela possibilidade de trocar informações sobre receitas, insumos, locais de vendas de equipamentos, avaliar suas cervejas em encontros de degustação, realização de cursos sobre áreas de interesse dos cervejeiros.

Segundo o cervejeiro "Barleywine", que trabalha atualmente em um brewpub $b^{6}$ em Curitiba, anteriormente, trabalhava com manutenção de ar-condicionado, atividade que manteve após sua inserção profissional no universo da cerveja, quando da premiação de uma de suas cervejas caseiras, num concurso da Associação do Cervejeiros do Paraná. A partir do prêmio, foi convidado para trabalhar como cervejeiro de um brewpub, sendo responsável por elaborar as receitas do bar e dos clientes que quisessem elaborar sua própria cerveja. Inicialmente, manteve sua atividade paralela e, hoje, após quatro anos, continua trabalhando no brewpub, tem sua própria marca de cerveja e pretende abrir, no próximo ano, uma cervejaria, e dedicar-se integralmente ao seu empreendimento.

Os cervejeiros artesanais desenvolvem uma relação específica entre os saberes experienciados na prática, e seu trabalho não é só um meio para o fim que o transcende, pois suas ideias de artesania fundam-se em uma habilidade desenvolvida em alto grau, na qual,

7 Brewpubs são os bares que produzem a própria cerveja no local e só as vendem ali mesmo. 
em dado momento, a técnica já não é mais uma atividade mecânica, mas que ele sente mais plenamente o que está fazendo, utilizando da reflexividade que dará um sentido a esta prática com muito mais profundidade (DUBAR, 2009).

O processo de elaboração da cerveja artesanal, segundo o entrevistado "IPA", passa pelo processo de aquisição dos equipamentos, compra dos insumos, até a fabricação da cerveja.

Foi em 2006 que eu comprei o meu primeiro equipamento de cerveja. Comprei um equipamento que eram duas panelinhas de vinte litros, um balde de vinte litros. Comprei um kit que era para fazer cerveja de vinte litros. Com malte, lúpulo, fermento, tudo junto, um kit. Eu me lembro que na época eu paguei setecentos reais e eu fiz uma receita. A primeira receita ficou super boa. Eu fiquei bem orgulhoso, porque eu tomei a cerveja.

Os cervejeiros artesanais são os autores das receitas, responsáveis pela fabricação das cervejas e no início da operação são também os vendedores das cervejas, a partir da visita a bares e restaurantes para ofertar sua bebida; portanto, desenvolvem e executam um trabalho específico que se baseia em conceitos de habilidade e competência, do ambiente afetivo da cervejaria e da saída do seu trabalho sob a forma de cerveja, que é reconhecida e apreciada por outras pessoas (PALMER et al., 2010). Os cervejeiros artesanais dão prioridade à criatividade, tanto no sentido de inovação, para criar algo novo e único, como também no sentido de constantemente "criar" algo, através da qualificação, seleção, preparação e combinações de ingredientes e materiais. A identidade de cervejeiros artesanais é, por conseguinte, um processo complexo, para que ele seja formulado em todo o espaço físico (a cervejaria), com os objetos materiais (matérias-primas, ingredientes, equipamentos, rótulos) e com os cervejeiros de outras cervejarias.

\section{Escolhas profissionais, estilos de vida e construção do mercado}

No contexto contemporâneo, onde as escolhas profissionais aparecem cada vez mais associadas aos estilos de vida, a redescoberta da valorização do trabalho como cervejeiro artesanal transformou o setor numa opção atraente para os jovens adultos, uma área inovadora e, ao mesmo tempo, diferente, que passou a atrair um contingente de aspirantes de classe média e média alta, que mudaram seus percursos profissionais para trabalharem com cervejas artesanais. Segundo Giddens, o estilo de vida

(...) Pode ser definido como um conjunto mais ou menos integrado de práticas que um indivíduo adota, não só porque essas práticas satisfazem necessidades utilitárias, mas porque dão forma material a uma narrativa particular de autoidentidade." (GIDDENS,1997, p. 75). 
Os estilos de vida tornaram-se uma das principais instâncias de construção de identidades, que afloram e ganham visibilidade no interior das práticas culturais. As maneiras de beber, comer, vestir, morar, associadas às escolhas literárias e artísticas, remetem a níveis de reconhecimento mais profundos - à classe social, à ocupação, mas também às opções éticas, políticas, estéticas e morais.

Neste processo, o cervejeiro artesanal vai ganhando visibilidade com a abertura, a partir da última década, de novas cervejarias, a multiplicação de publicações especializadas (livros, jornais, revistas, guias e manuais), dos programas de televisão, congressos, eventos, escolas voltadas à formação de cervejeiros e sommeliers. Tudo isso visa consolidar uma cultura cervejeira, produzindo o discurso público indispensável para que se possa avaliar a cerveja, posicioná-la no mercado e construir interesse por esse produto. Nesse contexto, o cervejeiro artesanal configura-se como agente cultural, como responsável por assinar e elaborar as cervejas artesanais, assim como o articulador da criação de associações e escolas de cervejas, pela experimentação e pela invenção estreitaram-se as colaborações com outros cervejeiros, intensificou o processo de trocas, promovendo o fortalecimento de uma nova rotina e impulsionando uma nova maneira de pensar o trabalho do cervejeiro, a produção, o mercado e os tipos de cervejas (BUENO, 2013).

Segundo o cervejeiro "Brown Ale", formado em educação física, personal trainer, dono de cervejaria com dois sócios, sendo ele o único que se dedica integralmente à cervejaria, integra a direção de associação de cervejarias do Rio Grande do Sul e do Brasil, e destaca o trabalho colaborativo entre as cervejarias:

\footnotetext{
Só que na indústria cervejeira, quando tu estás falando de indústrias concorrendo, umas contra as outras, entende, isso não é normal. E aí tu vê isso acontecendo no meio empresarial. Tu vê isso acontecendo aqui. Doze cervejarias uma trocando ideia com a outra o tempo inteiro, no whatsapp o pessoal trocando ideias de receita, de processo, indicando fornecedor, e não sei o quê, um ajudando o outro, isso é a essência [...] elevada num outro patamar.
}

A expansão do consumo na sociedade contemporânea, de um modo geral, e no Brasil em particular, teve um impacto transformador na organização e na dinâmica das cervejas artesanais, que passou de setor associado aos ofícios e ao artesanato à esfera de produção cultural legitimada. Esse movimento levou a um reconhecimento e prestígio dos cervejeiros artesanais, associado a uma mudança de status (de artesãos a produtores intelectuais), indicando transformações correlatas no trabalho e no modo de produção. A sociedade de massa, a industrialização, a exigência de padrões pelo mercado e de normatizações pela indústria, transformaram as cervejas artesanais em universo valorizado e altamente complexo.

Da mesma forma, a literatura considera que os consumidores estão dispostos a pagar um prêmio para os produtos que lhes permitem sinalizar essa relação, em parte porque eles 
derivam do estado, os produtos, "os valores simbólicos" que, segundo Velthuis (2005, p.142), “"Mudou a atmosfera do mercado e transformou-o de um mercado de arte próprio em um mercado de commodities ou de investimento". Os cervejeiros, assim como os marchands de arte, fazem uso de associação de diferentes significados para as transações econômicas - artista/ distribuidor, revendedor/coletor - a fim de "marcar e simbolizar relações sociais com os artistas e colecionadores" (VELTHUIS, 2005, p.75).

Carroll e Swaminathan (2000) destacam que produtores especializados, como no caso da cerveja artesanal, permitem aos consumidores manifestarem-se acerca da qualidade e da autenticidade do produto e, ao mesmo tempo, optarem por um produto especializado. Eles estão atribuindo ao consumo uma ação de autoexpressão, que implica também em distinção social.

Segundo o cervejeiro "IPA"

Porque quando a gente começa a consumir e não é a revolução da cerveja artesanal, é a revolução do alto consumo agregado, é aquele que para de ir no Mac Donalds e vai para hamburgueira. Ele para de comer pizza hut e vai fazer a sua massa de pizza em casa, porque é mais legal, porque fica mais gostoso, etc. etc. É aquele que vai parar de consumir o bastantão e ele vai começar a consumir, daqui a pouco na feira que tem no final de semana, orgânica, de produto que ele sabe a procedência, ou seja, é consumo mais informado

Neste sentido, os gostos, na perspectiva bourdieusiana, confundem-se com a própria disposição estética:

\begin{abstract}
[...] é também expressão distintiva de uma posição privilegiada no espaço social [...] Como toda espécie de gosto, ela une e separa: sendo o produto dos condicionamentos associados a uma classe particular de condições de existência, ela une todos aqueles que são produtos de condições semelhantes, mas os distinguindo de todos os outros e, a partir daquilo que têm de mais essencial, já que o gosto é o princípio [...] daquilo que serve de base para se classificar a si mesmo e pelo qual se é classificado" (BOURDIEU, 2007, p. 56)
\end{abstract}

As preferências dos consumidores por um produto "autêntico" são, portanto, de certa forma, destacadas pelas características socialmente construídas. No caso da cerveja artesanal, a cor, o aroma, o estilo da cerveja, os ingredientes, o cheiro são atributos relevantes para identificar o produto e lhes conferir uma identidade que está associada a um cervejeiro, e que também contribuem para a identidade dos consumidores.

Segundo o cervejeiro "IPA", quando da abertura de sua cervejaria e pela escolha em não produzir cervejas no estilo Pilsen, ele reforça esta ideia de produzir algo autêntico.

O meu planejamento foi esse aqui eu vou fazer isso aqui. Não, mas é que toda a cervejeira faz Pilsen, tá mas e aí? Eu não quero ser todo cervejeiro eu quero fazer algo diferente. E eu adoro Pilsen, não me entenda mal. O pessoal acha que eu odeio Pilsen, cara eu acho muito bom. Só que na proposta que eu tinha de fazer da "cervejaria" a gente 
quis criar coisas que tivessem um diferencial de mercado forte. E que óbvio, eu ia ter muito mais trabalho para conseguir consolidar, mas ao mesmo tempo, no momento que eu conseguisse consolidar, eu teria dado um grande passo. E que é um nicho.

Os cervejeiros artesanais das pequenas cervejarias têm mais probabilidades do que os seus concorrentes de maior porte de personalizar as suas ofertas para as necessidades do cliente, considerando que estes produtores atuam em nichos específicos, enquanto os grandes produtores atuam em grandes segmentos (CARROL et al., 2009), pois os produtores artesanais investem sua personalidade no objeto produzido, preocupam-se com o trabalho que estão realizando; ao mesmo tempo, os objetos produzidos são vistos como manifestações de sua identidade e que representam o encontro de habilidades cognitivas, manuais, ingredientes, ferramentas, equipamentos e o ambiente de produção, que garantem uma materialidade tangível, a ser saboreada e apreciada pelos consumidores.

Para a cervejeira "Ambar"

Eu acho que hoje o nosso consumidor ele quer consumir mais informação. Ele não quer consumir só o produto. Ele quer saber de onde veio, ele quer conhecer as pessoas que fazem. Ele quer interagir, ele quer ir na fábrica, sabe, então esse é o consumidor moderno que sabe.

De acordo com Steiner (2006), o mercado como estrutura social é formado a partir da relação de confiança entre os atores que dele participam, além da história e da coordenação social existentes no próprio mercado, com suas estruturas, conflitos e dependências (ABRAMOVAY, 2004). Acredita-se, com isso, que a criação desse mercado deverá vir como resultado de um trabalho de coordenação da própria comunidade sobre si mesma, mesmo porque não é possível que ele surja como um resultado espontâneo (STEINER, 2006). Esse mercado leva em consideração os fatores relacionais, políticos, culturais e outros que intervêm na sua formação, paralelamente aos fatores econômicos. Nessa construção, um estudo importante é o relativo ao levantamento das referências comuns, tais como a origem da cerveja, a forma de produção e os atributos do produto, além dos atores sociais que participam do processo e que farão parte do trabalho de construção do tipo de produto, a cerveja artesanal que será lançada no mercado.

É preciso assegurar-se de que os produtores não se comportem de maneira oportunista, para tirar vantagem das diversas formas de comercialização, (...) o que enfraqueceria o conjunto de produtores. (STEINER, 2006, p. 50).

Pierre Bourdieu sugere que o estudo de um determinado espaço social passe pelo estudo dos principais agentes que atuam nele, pois são eles que 
(...) criam o espaço, isto é, o campo econômico, que só existe pelos agentes que se encontram nele e que deformam o espaço na sua vizinhança, conferindo-lhe uma certa estrutura. Dito de outro modo, é na relação entre as diferentes "fontes de campo", isto é, entre as diferentes empresas de produção, que se engendram o campo e as relações de força que o caracterizam. (BOURDIEU, 2005, p. 23).

O mercado é analisado como um fenômeno econômico embutido numa estrutura de relações sociais que tanto podem ser tornadas maleáveis pelas forças da estrutura social e da ação coletiva, como ficar bloqueadas por essas forças (GRANOVETTER, 2003). As relações sociais influenciam a forma como o produto é visto, especialmente nos festivais e feiras de cerveja artesanal. Nestes espaços é possível o contato entre os produtores de cervejas artesanais e os consumidores, permitindo formar-se uma imagem acerca do objeto de consumo, através da compra de um copo da cervejaria, de uma camiseta, que possibilitam uma lembrança permanente da cervejaria.

É neste contexto que os cervejeiros artesanais lidam atualmente com os desafios contemporâneos do mercado de trabalho e da empresarialização de si como pessoa e profissional, quer da forma como novos segmentos de mercado são socialmente estruturados como alternativas, simultaneamente, laborais e de consumo, ao mesmo tempo em que o conjunto do seu trabalho envolve uma complexidade de subjetividades, estratégias e criativização, para produzir algo autêntico para se destacar em um mercado em crescente expansão.

A expansão de microcervejarias, ao longo da última década, é decorrente de um percurso de empresarialização de cervejeiros artesanais, que transformam um hobby de fazer cerveja em casa, em panelas, para o consumo próprio e para beber entre amigos, em uma nova carreira, reconvertendo suas trajetórias profissionais para a identificação como cervejeiro artesanal, responsável pela abertura de novas microcervejarias, utilizando-se do conhecimento e das habilidades aprendidas e desenvolvidas neste fazer artesanal, para a criação de novas receitas e testagem de novos ingredientes, com os quais são produzidos um pequeno número de garrafas para serem provadas e, posteriormente, colocadas no mercado.

Os recentes movimentos de maximização de valores, que modificaram as esferas tradicionais do mundo do trabalho como competência, profissionalização, expertise e desempenho encontram-se aliados aos valores de criatividade, ludicidade, expressividade e do prazer, e as novas relações colaborativas, em contraponto à competividade. Estes valores, articulados ao estudo do empreendedorismo contribuirão, de forma efetiva, para o crescimento econômico e, subsequentemente, para a criação de novos empregos. A valorização do trabalho criativo, a educação para o empreendedorismo e o aperfeiçoamento tecnológico constituem a raiz para que novos processos de inserção profissional, pela via da inovação, sejam efetivados. 


\section{Referências}

ABRAMOVAY, R. Entre Deus e o diabo: mercados e interação humana nas ciências sociais. Tempo Soc. São Paulo, v. 16, n. 2, p. 35-64, nov. 2004.

ALVES, N. Inserção Profissional e Formas Identitárias. Lisboa: Educa/UI\&DCE, 2009. . Juventudes e Inserção Profissional. Lisboa: Educa/UI\&DCE, 2008.

BARBOSA, L. Sociedade de Consumo. Rio de Janeiro: Jorge Zahar, 2004.

BECK, U. Sociedade global de risco: na busca da segurança perdida. São Paulo: Editora 34, 2011.

BECKER, H. Mundos da arte. Lisboa: Livros Horizonte, 2010.

BOLTANSKI, L.; CHIAPELLO, È. O novo espírito do capitalismo. São Paulo: Martins Fontes, 2009.

BOURDIEU, P. A distinção: crítica social do julgamento. São Paulo: Edusp, 2007.

O Campo Econômico. Política \& Sociedade, n. 6, 2005, p. 15-57.

BUENO, M. L. . Gastronomia e sociedade de consumo. Tradições culturais brasileiras e estilos de vida na globalização cultural. In: REINHEIMER, P.; SANT’ANNA, S. Parracho (Org.) Manifestações artísticas e ciências sociais: reflexões sobre arte e cultura material. Rio de Janeiro: CULTIS, UFRJ/Folha Seca, 2013.

CARROLL, G. R; SWAMINATHAN, A. Why the Microbrewery Movement? Organizational Dynamics of Resource Partitioningin the U.S. Brewing Industry. American Journal of Sociology, 106:715-62, 2000.

and WHEATON, D.R. The organizational construction of authenticity: an examination of contemporary food and dining in the U.S. Research in Organizational Behavior 29: 255-282, 2009.

CAMPBELL, C. The Craft Consumer: Culture, craft and consumption in a postmodern society. Journal of Consumer Culture, 5: 23, 2005.

DOUGLAS, M.; ISHERWOOD, B. O mundo dos bens: para uma antropologia do consumo. Rio de Janeiro: Editora da UFRJ, 2004.

DUBAR, C. A crise das identidades: a interpretação de uma mutação. São Paulo: Editora USP, 2009.

A socialização: construção das identidades sociais e profissionais. São Paulo: Martins Fontes, 2005.

Trajetórias sociais e formas identitárias: alguns esclarecimentos conceituais e metodológicos. Educação \& Sociedade, 1998, 19 (62), 13-30.

DUBET, F. Sociologia da experiência. Lisboa: Instituto Piaget, 1996.

FERREIRA, V. S. Artes e manhas da entrevista compreensiva. Saúde e Sociedade, São Paulo, v. 23, n. 3, p. 979-992, sep. 2014.

Das Belas Artes à arte de tatuar: dinâmicas recentes no mundo português da tatuagem. In: ALMEIDA, M. I. M., PAIS, J. M. (Orgs.). Criatividade \& Profissionalização: Jovens, subjectividades e horizontes profissionais. Lisboa: Imprensa de Ciências Sociais, 2013, p. 55-99.

GARCIA-PARPET, M.-F. Mundialização dos mercados e padrões de qualidade: “vinho, o modelo francês em questão". Tempo Social, São Paulo, v. 16, n. 2, p. 129-150, nov. 2004.

Estilos de vida e maneiras de beber: a oferta dos bens de prescrição enológica. In: BUENO, M.L., CAMARGO, L.O.L. Cultura e consumo: estilos de vida na contemporaneidade. São Paulo: Editora Senac, 2008.

GEERTZ, C. A interpretação da cultura. Rio de Janeiro: LTC, 2008.

GIDDENS, A. Modernidade e identidade pessoal. Lisboa: Oeiras, 1997.

GRANOVETTER, M. Ação econômica e estrutura social: o problema da incrustação. In: MARQUES, R.; PEIXOTO, J. (org.). A Nova Sociologia Econômica. Oeiras: Celta Editora, 2003.

LAHIRE, B. Sucesso escolar nos meios populares: as razões do improvável. São Paulo: Ática, 1997.

. O homem plural: os determinantes da ação. Petropólis, RJ: Vozes, 2002. 
Retratos sociológicos: disposições e variações individuais. Porto Alegre, Artmed, 2004.

Patrimônios individuais de disposições. Para uma sociologia à escala individual. In: Sociologia. Problemas e Problemáticas. n. 49, 2005.

A cultura dos Indivíduos. São Paulo: Artmed Editora, 2006.

Maciel, A. F. (2017). Cultural Tensions between Taste Refinement and Middle-Class Masculinity: A Case Study of Craft Beer Aficionados. In N. G. Chapman, J. S. Lellock and C. Lippard (Ed.), Untapped: Exploring the Cultural Dimensions of Craft Beer (pp. 203-21). West Virginia University Press.

MALINOWSKI, B. C. Argonautas do Pacífico Ocidental. São Paulo: Abril Cultural, 1976.

O'CONNOR, E. Embodied knowledge: The experience of meaning and the struggle towards proficiency in glassblowing. Ethnography 6 (2), 183e204, 2005.

PAIS, J. M.; FERREIRA, V. S. Tempos e Transições de Vida: Portugal ao Espelho da Europa. Colecção Atitudes Sociais dos Portugueses, Lisboa:Imprensa de Ciências Sociais, 2010.

PALMER, C., COOPER, J., BURNS, P. Culture, identity and belonging in the "culinary underbelly". Int. J. Cult.

Tourism Hospit. 4 (2), 311e326, 2010.

PODOLNY, J. M. 1993. A Status-Based Model of Market Competition. American Journal of Sociology 98:82972.

POLANYI, K. A grande transformação. As origens da nossa época. Rio de Janeiro: Campus, 2000.

SAHLINS, M. Cultura e razão prática. Rio de Janeiro: Jorge Zahar Ed., 2003.

SEBRAE - Serviço Brasileiro de Apoio às Micro e Pequenas Empresas. Dados Disponíveis em: <http://www. sebrae.com.br/setor/comercio-varejista/o-setor/cenario-e-tendencia $>$. Acesso em julho de 2016.

SENNETT, R. Juntos. Rio de Janeiro: Record, 2012.

O artífice. Rio de Janeiro: Record, 2012.

SCHNEIDER, Sérgio. Prefácio. In: RADOMSKY, G. O poder do selo. Imaginários ecológicos, formas de certificação e regimes de propriedades intelectual no sistema agroalimentar. Porto Alegre: Editora da UFRGS, 2015.

Schnell, S. M. Deliberate identities: Becoming local in America in a global age. Journal of Cultural Geography, 2013, 30 (1): 55-89

STEINER, P. A Sociologia Econômica. São Paulo: Atlas, 2006.

VALDEZ, M. E., DOKTOR, R. H., SINGER, A. E., \& DANA, L.-P. Impact of tolerance for uncertainty upon opportunity and necessity entrepreneurship. Human Systems Management, 30(3), 145-153, 2011.

VELTHUIS, O. Talking Prices: symbolic Meanings of Prices on the Market for Contemporary Art. New Jersey, EUA: Princeton Studies in Cultural Sociology, 2005.

ZELIZER, V. A. Dualidades perigosas. Mana, Rio de Janeiro, v. 15, n. 1, p. 237-256, apr. 2009.

Dinheiro, poder e sexo. Cadernos Pagu, Campinas, n.32, p. 135-157, jun. 2009.

Recebido em: 16/01/2018

Aceito em: 31/03/2018 